This item was submitted to Loughborough's Research Repository by the author.

Items in Figshare are protected by copyright, with all rights reserved, unless otherwise indicated.

\title{
Enhancing the stability of the leisure nostalgia scale: assessment of the measurement invariance between two different leisure populations
}

PLEASE CITE THE PUBLISHED VERSION

https://doi.org/10.1080/02614367.2019.1653356

\section{PUBLISHER}

Taylor \& Francis (Routledge)

\section{VERSION}

AM (Accepted Manuscript)

\section{PUBLISHER STATEMENT}

This is an Accepted Manuscript of an article published by Taylor \& Francis in Leisure Studies on 20 Aug 2019, available online: https://doi.org/10.1080/02614367.2019.1653356

\section{LICENCE}

CC BY-NC-ND 4.0

\section{REPOSITORY RECORD}

Cho, Heetae, Do Young Pyun, and Seunghyun Lim. 2019. "Enhancing the Stability of the Leisure Nostalgia Scale: Assessment of the Measurement Invariance Between Two Different Leisure Populations". Loughborough University. https://hdl.handle.net/2134/9963755.v1. 
1 Running head: INVARIANCE OF THE LEISURE NOSTALGIA SCALE

2

3

4

5

6

7

8

9

10

11 Enhancing the Stability of the Leisure Nostalgia Scale: Assessment of the Measurement

Invariance between Two Different Leisure Populations 


\section{Abstract}

2 Nostalgia has recently garnered attention in the field of leisure, and a leisure nostalgia scale

3 (LNS) has been developed. However, the LNS was initially developed and validated in one

4 Eastern country, Singapore, and has not been tested with other populations for its

5 applicability. Therefore, the purpose of this study was to examine the invariance of the LNS

6 to determine if the specified factorial structure of the scale is identical across different leisure

7 populations in the UK and Singapore. The results showed that the LNS presented the same

8 number of factors from the UK and Singapore data sets and supported the stability of the LNS

9 factor structure, indicating that it can be confidently applied across different leisure

10 populations from different countries. Although the LNS was fairly invariant across the two

11 data sets, the findings revealed three items in socialisation and three items in personal identity

12 to be non-invariant. The results of this study contribute to expanding future nostalgia

13 research and a deeper understanding of leisure nostalgia.

14 Keywords: Leisure, nostalgia, scale development, measurement invariance 


\section{Introduction}

Recently, nostalgia has also garnered attention in the field of leisure. Cho, Pyun, and

3 Wang (2019) developed a Leisure Nostalgia Scale (LNS) based on a classification of

4 nostalgia (Cho, Ramshaw, \& Norman, 2014). The LNS was initially developed and validated

5 in one Eastern country, Singapore. However, the scale has not been tested for its external

6 validity to enhance its generalisability. According to Buil, de Chernatony, and Martínez

7 (2012), the measurement model should be tested in different countries with different people to

8 identify its applicability. From a psychometrical viewpoint, it is also imperative for the

9 measurement model to be tested on two or more populations using the same theoretical

10 structure to avoid biased evaluations (Dimitrov, 2010). This study is motivated with a question

11 of whether different leisure populations would perceive its items in the similar way as it was

12 designed.

13 Therefore, this research aims to examine the psychometric properties of the LNS

14 within the UK and Singapore. In particular, the study tests the invariance of the LNS to

15 determine if its specified factorial structure of is identical across the populations in the UK

16 and Singapore. It is hypothesised that the LNS measures were invariant with respect to factor

17 loadings, covariances, and error variances across the two different populations (see Figure 1).

18 Lastly, it is worthwhile to introduce the terms popularly used in this study. The measurement

19 invariance refers to "the instrument of the measurement is operating in exactly the same way,

20 and that underlying construct being measured has the same theoretical structure for each

21 group under study" (Byrne, 2004, p. 272). Accordingly, a non-invariant measure can be understood as differential factorial structures of the measure led by different interpretations of the item content among people (Byrne, 1993). 
Stern (1992) stated that nostalgia is an emotional state in which individuals romanticise an earlier period. Similarly, Davis (1979) explained nostalgia is the selective reminiscing of a past event associated with positive feelings. The retrieval of past memory may involve experience, object, and event (Fairley, 2003). Based on this perspective of nostalgia and the existing body of literature, Cho et al. (2014) defined nostalgia as the recollection of a positive past, whereas negative feelings concerning the present and the future can influence the level of nostalgia. Additionally, nostalgia is identified as a complex emotion as it is a feeling that can be felt even without the first-hand experience of positive past events. Regarding this, Stern (1992) asserted nostalgia can be elicited even through vicarious experiences, such as through pictures, movies, print media, and word of mouth. Thus, in order to simplify and better understand the multidimensional nature of nostalgia, Cho et al. (2014) developed a classification of nostalgia.

The classification of nostalgia is designed to analyse an individual's nostalgic behaviour. It consists of two dimensions (i.e., structure and purpose of nostalgia) with four components (i.e., experience, socialisation, personal identity, and group identity; Cho et al., 2014). The structure of nostalgia is an object- and relationship-based nostalgia, which implies the requirement of a tool to generate nostalgia through sport objects and social experience. The purpose of nostalgia focuses on the value people place on their past experience itself and identity. Accordingly, these two dimensions provide the four-way classifications: nostalgia as experience, socialisation, personal identity, and group identity.

Firstly, nostalgia as experience points that nostalgic feelings are evoked by one's personal past experience, which involves sport attributes, such as sport athletes, teams, sport venues, and atmosphere (Cho et al., 2014). Individuals may be attached to a certain team player, a coach or a team among many other aspects of experience. In addition, past studies have found sport facilities play a significant role in the experience evoking nostalgia as 
1 individuals may grow sentimental longing for stadiums and other iconic places (Seifried \&

2 Meyer, 2010). Secondly, individuals form nostalgic feelings through social interaction. This

3 can occur through past experiences, such as interactions with others. For example,

4 recollection of sport-related childhood memories associated with some form of social

5 interaction may induce nostalgia among individuals. In the context of leisure, most leisure

6 activities involve more than a single person to participate. Hence, social interaction at such

7 leisure/recreation activities has the possibility of forging positive memories, evoking

8 nostalgia. Thirdly, nostalgia as personal identity is the identification of an individual in a

9 leisure service setting, such as a team supporter in the stadium crowd. One's level of

10 identification with the sport is important to understand personal identity. This factor of

11 nostalgia is based on the identity theory by Hogg, Terry, and White (1995) and explains the

12 relationship between sport and nostalgia in terms of the individual's behaviour, cognitive

13 state, and emotional response toward their sport. In other words, a fan's participation in a

14 sporting event can create an identity, which leads to nostalgic feelings. Likewise, individuals

15 who participate in leisure see that this particular leisure activity contributes to their personal

16 identity. For instance, the sense of pride that comes from being recreationally involved, such

17 as a being a member of a book club, adds value to one's self-concept. Lastly, nostalgia as

18 group identity is based on Tajfel and Turner's (1979) social identity theory and Festinger's

19 (1954) social comparison theory. It concerns people attending a sporting event and their self-

20 evaluation through comparison. A social identity is formed based on the relationship or

21 connection to a group. The group's acknowledgment of an individual creates the feeling of

22 having a group identity, and memories with the group can then lead to nostalgia. In addition,

23 Fairley $(2003,2009)$ stressed collective emotion plays a crucial role in group identity.

24 Based on the classification of nostalgia, Cho et al. (2019) developed the LNS and

25 found a five-factorial structure of nostalgia, instead of the four-factor structure originally 
1 proposed by Cho et al. (2014), including leisure experience, environment, socialisation,

2 personal identity, and group identity. The initial concept of nostalgia as experience (Cho et

3 al., 2014) is now split into two separate domains: leisure experience and environment.

4 Nostalgia as leisure experience accounts for a more general view of an experience. On the

5 other hand, leisure environment focuses specifically on the overt emotional attachment of an

6 experience, such as the place, facilities, and equipment, as highlighted by Fairley (2003) and

7 Seifried and Meyer (2010). Nostalgia as an experience is a broad term used to hold many

8 other aspects of an experience, like sport objects, such as athletes, teams, sport venues,

9 atmosphere, and the past personal experiences associated with it. Therefore, the dissection of

10 this domain into specific domains allows better understanding in the precision of knowing

11 where the nostalgia stems from. While leisure experience and leisure environment fit into the 12 nostalgia as experience domain of Cho et al.'s (2014) model, the split components represent

13 distinct characteristics in the context of leisure.

\section{Method}

\section{Participants and Procedure}

Two groups of samples were recruited from two different populations. One group consisted of 450 event participants and spectators attending a popular sporting event in Singapore. After excluding two participants indicating that they did not have any positive nostalgic experiences, 448 samples who reported positive leisure memories in the past $(M=$ $5.63, S D=1.06)$ were utilised for the study. Out of 448,267 participants $(59.6 \%)$ were male and 181 participants $(40.4 \%)$ were female. An average age was $28.1(S D=9.53)$, and racially, a large majority of the participants was Chinese (90.0\%), followed by Malay (3.1\%) and Indian (2.2\%). The other group included 207 students attending a large university in the East Midland of the UK. They were also asked by one question to determine a nostalgic feeling level. All respondents answered that they had positive memories toward their previous leisure 
1 experiences $(M=6.33, S D=0.90)$. Similar with the Singapore group, $57.0 \%$ and $43.0 \%$ of

2 the participants were male and female, respectively, and their average age was $21.7(S D=$

3 3.63). Racially, white (68.1\%) was a dominant group, followed by Asian (17.4\%), Black-

4 African/Caribbean (5.3\%) and Latin American (2.4\%).

5 Measures

6 Grounded on the conceptualisation of nostalgia in tourism (Cho et al., 2004), recently

7 Cho et al. (2019) developed the leisure nostalgia scale. The scale includes five dimensions

8 with 33 items: leisure experience (five items), environment (seven items), socialisation (six

9 items), personal identity (seven items) and group identity (eight items). For the invariance

10 testing, all 33 items were retained and measured using a 7-point Likert scale, varying from

11 strongly disagree (1) to strongly agree (7).

\section{Data Analysis}

13 The study utilised Byrne's (2004) multigroup invariance procedure. The analyses

14 included three phases. Phase One aimed to determine a baseline model that best fits the data

15 of each group, with the considerations of both parsimony and substantive meaningfulness

16 (Byrne, 2004). If this model is suitable for both groups, it is utilised as a baseline model for

17 the main invariance test. Phase Two was designed to further test the invariance of the

18 individual parameters (i.e., factor loadings, covariances, and error variances) across the

19 groups. For the model comparisons, a chi-square difference test was used as the index of

20 difference in fit. Specifically, the study tested the overall fit of the baseline model across two

21 groups simultaneously and obtained the baseline values. These baseline values were then compared with a fully constrained model, where all loadings, covariances, and error variances were imposed to be equal across two groups. If the test rejects the null of equality of a certain

24 set of parameters (e.g., factor loadings), it shows that there is at least one non-invariant

25 parameter in this set, and further investigations for this parameter set need to be conducted to 
1 detect problematic parameter(s) in Phase Three. Through this multistep process, testing for

2 invariance of all parameters, except error variances, between the UK and Singapore groups is

3 completed. This is because testing for the equivalence of individual error variances is

4 considered too stringent and restrictive (Byrne, 2004).

5

6

7

\section{Results}

\section{Phase One: Testing for the Validity of the Nostalgia Measurement Model}

Based on priori knowledge (Cho et al., 2019), the five-dimensional measurement with 33 items was selected, and two independent CFAs were conducted as a prerequisite to see if the degree of correspondence between the model and each data group is satisfactory. The goodness-of-fit tests revealed that the model fitted to each data well: $\chi^{2}(485)=2026.15$, RMSEA $=.090, \mathrm{CFI}=.96, \mathrm{NFI}=.95, \mathrm{IFI}=.96$ for the Singapore group and $\chi^{2}(485)=$ 1122.92, $\mathrm{RMSEA}=.078, \mathrm{CFI}=.96, \mathrm{NFI}=.93, \mathrm{IFI}=.96$ for the UK group. All index values met the recommended cut-offs (Kelloway, 1998). Since the adequacy of the model was crossvalidated, the current measurement model was determined as a baseline model for further invariance tests.

\section{Phase Two: Testing for Invariance of All Parameters (see Table 1)}

First, the goodness-of-fit of the model across the two groups was tested simultaneously first. The baseline model still showed a fairly good fit between two groups: $\chi^{2}(970)=$ 3149.07, $\mathrm{RMSEA}=.08, \mathrm{CFI}=.96, \mathrm{NFI}=.94$, and $\mathrm{IFI}=.96$. The chi-square value $(3149.07)$ and degree of freedom (970) from this unconstrained model (Entry 1) served as baseline values for the subsequently constrained models (Entry 2-5). As a first step, a model which all parameters (loadings, covariances, and error variances) were imposed to be equal between two groups was compared with the baseline model which was fully unconstrained (Entry 2). The test rejected the null of equality $(p<.01$, where the cut-off chi-square value at $\Delta d f[76]$ was 107.58), failing to support the identical pattern of the fixed and nonfixed parameters 
1 across the data sets. Accordingly, the subsequent tests for the equality of factor loadings

2 (Entry 3), covariances (Entry 4), and error variances (Entry 5) were conducted in the

3 hierarchical ordering of the nested models. While the test failed to reject the null hypothesis

4 for covariances, unfortunately, the test rejected the null of all factor loadings and error

5 variances at the .01 probability level. Given the findings, it was deemed that there was non-

6 invariance of factor loadings and error variances between two samples. To pinpoint individual

7 problematic item(s), further investigations on the equality of the factor pattern in the model

8 were carried out in Phase 3. With the aforementioned reason, no further actions for error

9 variances were taken.

\#\#\#Insert Table 1 here\#\#\#

11 Stage Three: Testing for Invariance of Factor Loadings (see Table 2 and 3)

First, the five constrained models, where the factors in leisure experience (Entry 3),

environment (Entry 4), socialisation (Entry 5), personal identity (Entry 12), and group identity (Entry 20) were imposed to be equal across the groups, were prepared and compared with their respective competing models. Entry 3, Entry 4, and Entry 20 report that the comparisons of the constrained models were not statistically significant, indicating all factor loadings in leisure experience, environment, and group identity were invariant. However, Entry 5 and Entry 12 show that the tests rejected the null hypotheses of both socialisation and group identity. From the findings, it was logical to assume that any inequality of factor

20 loadings across the groups lied within these factors. Then, we proceeded to constrain loadings 21 in each factor separately and compared them with their competing model. As a results, three items (S3, S4, and S5) in socialisation and three items (PI1, PI2, and PI4) in personal identity were found to be not invariant, concluding that the different groups did not respond to the six 24 items exactly in the same way. 
1 A summary of the findings is shown in Table 3. For better comparisons in the factor

2 loading regression paths between two groups, both standardised and unstandardised

3 coefficients are also reported in this Table.

\section{\#\#\#Insert Table 3 here\#\#\#}

\section{Discussion}

The LNS was designed as a five-dimensional scale. While Cho et al. (2019) provided the empirical justifications to support its overall and internal model fit using the samples in Singapore, its validity with different populations has not yet been soundly evidenced.

Through the rigor of a series of invariances tests, the findings of this study supported the LNS to present the same number of factors from the independent samples of the UK and Singapore and cross-validated the stability of the LNS factor structure. With the confirmations, the LNS can be confidently applied across different leisure groups from different countries. Although the LNS was fairly invariant across the two data sets, the findings of this study revealed six items to be non-invariant. First, out of the six items in socialisation, three items were found to be non-invariant. Scrutiny of the contents for these items revealed the possibility of the commonality among the three socialisation items, which were related to 'relationship development' (e.g., building, socialising, and making). Similarly, three items in the personal identity factor were found to be non-invariant. The commonality among the three constructs was the inclusion of the word, 'lover'. In addition, the term might be interpreted in different contexts between the UK and Singapore respondents according to their culture and linguistic comprehension.

These findings provide a better understanding of the measurement of LNS and its fit to different leisure groups. That is, the differences in the two data sets may be accounted for by the cultural differences between the UK and Singapore. Unlike Asian countries, European culture emphasises the importance of individualism, such as individual expressions, making 
1 them respond in a more straight-forward manner. Specifically, western countries, like the UK,

2 emphasise the tenets of liberalism. Therefore, individuals raised in these societies are

3 encouraged to value their individual rights to voice their own opinions (Jackson \& Wang,

4 2013). These opinions do not need to conform to the majority's view and are accepted freely.

5 For example, western people may prefer participating leisure activities alone (e.g., workout at

6 gym) rather than with others and may perceive feeling of nostalgia differently from positive

7 memories related to socialising with others. However, Eastern Asian countries, like

8 Singapore, adopt Confucianism into their societal values, resulting in a collectivist society

9 (Chiu, Leung, \& Hong 2011). Collectivist societies uphold common values and value social

10 harmony over individual interests (Kacen \& Lee, 2002). Hence, individuals raised in such

11 societies behave in a manner that does not deviate from the majority of society. In the same

12 vein, eastern people may perceive nostalgic feeling by recalling positive memories with

13 others (e.g., playing with friends). The influence of the different cultural orientations of the

14 two countries may have led to the difference in the results of the two data sets.

In addition, Asians are found to adopt a dialect that places situational factors as the center of focus. Therefore, eastern people are mindful of situational contexts when they need to explain their behaviour (English \& Chen, 2011). On the other hand, western people emphasise the importance of rational thinking and the understanding of information to be aligned to form internal coherence. This results in a decontextualised way of expression (English \& Chen, 2007). The two differences in dialectical approach imply that Asian people understand words by taking into consideration situational factors while western people synthesise words to form internal coherence. Hence, the term, 'lover' may have been misleading each other. More commonly used words such as 'fan' may have been a better 24 choice of word. 
1 evidence of the usefulness and applicability of the LNS in different cultural populations.

2 Previous studies contended that nostalgia is a useful tool in understanding individuals'

3 behaviours, particularly, in the field of consumerism (Muehling \& Pascal, 2011). This study

4 will broaden the focus of nostalgia into the field of leisure. Consequently, the findings of this

5 study provide useful practical implications for leisure practitioners. For example, this study

6 substantiates individuals to maintain identity through the aspects of nostalgic experiences that

7 include memorable places, establishing a link between the past and present (Aden, 1991) and

8 rituals (Fairley, 2003). In accordance with this, leisure marketers can develop programmes,

9 activities, and events that focus on collective elements, such as establishing and incorporating

10 shared values and rituals. In addition, they may arrange visits to historically significant places

11 relevant to particular leisure activities. As a result, nostalgia will be enhanced, leading to

12 continuous leisure participation.

\section{Conclusion}

14 The study examined the factorial invariance of the responses by the UK and Singapore

15 populations to the LNS. Byrne Shavelson, and Muthén (1989) and Marsh and Hocevar (1985)

16 took into consideration the difficulty to set a requirement of metric invariance requirement

17 and noted that when the nonvariant items are considered to be a minor portion of the model,

18 the nonvariant items may not have an insignificant effect on results of a study. Therefore, the

19 results of this study support the scale to be stable and successfully place the LNS in the study

20 of nostalgia as a measurement tool in the context of leisure. This study revealed six non-

21 invariant items that may be due to the commonality between the items. The commonality may

22 have caused the individuals to understand the linguistic terms differently, resulting in

23 different interpretations. However, given the six items showed acceptable or high loading

24 values on each factor, future research needs to modify these non-variant items based on

25 contextual understanding of research participants and reexamine the concept of nostalgia. For 
1 example, the term 'lover' in the personal identity items could be replaced with 'fan'. In

2 addition, the non-invariance in the socialisation items could be caused by using the sentences

3 starting with the word 'memories'. The respondents could be confused by either positive or

4 negative memories in the past when reading each statement. It is also possible that the

5 respondents' unsatisfactory present circumstance or uncertain future status could affect their

6 responses. Thus, future research could consider changing the word 'memories' to 'positive

7 feelings for the past'. Next, future research could consider possible cultural differences of

8 their target populations, which would strengthen the applicability and the usefulness of the

9 LNS. There is an evident difference in leisure participation between different cultures (Veal,

10 2016). For a broader universality and applicability across cultures, the LNS should be

11 validated in more culturally diverse contexts such as South America, Nordic and Middle East.

12 Furthermore, according to Havlena and Holak (1991), the tendency to engage in nostalgic

13 feelings varies over the course of the one's lifetime. However, samples in this research did

14 not include various age groups, predominantly including young generation only. Taking this

15 notion into consideration, a future research could recruit samples from different age groups to

16 better validate the LNS. Lastly, it is necessary to examine different types of leisure activity in

17 a future research. Leisure activities include diverse types of activity (e.g., passive or active),

18 from watching TV to playing sports. Given different dispositions of each leisure type, the

19 LNS can be further examined by types of leisure to enhance its stability. 


\section{References}

2 Buil, I., de Chernatony, L., \& Martínez, E. (2012). Methodological issues in cross-cultural research: An overview and recommendations. Journal of Targeting, Measurement and Analysis for Marketing, 20(3-4), 223-234.

Byrne, B. M. (1993). The Maslach Burnout Inventory: Testing for factorial validity and invariance across elementary, intermediate and secondary teachers. Journal of Occupational and Organizational Psychology, 66, 197-212.

Byrne, B. M. (2004). Testing for multigroup invariance using AMOS: A road less traveled. Structural Equation Modeling, 11(2), 272-300.

Chiu, C. Y., Leung, K. Y., \& Hong, Y. Y. (2010). Cultural processes: An overview. In A. K. Leung, C. Chiu, \& Y. Hong (Eds.), Cultural processes: A social psychological perspective (pp. 3-22). New York: Cambridge University Press.

Cho, H. (2019). Importance of leisure nostalgia on life satisfaction and leisure participation The Service Industries Journal. Advance online publication. doi: $10.1080 / 02642069.2019 .1567714$

Cho, H., Pyun, D. Y., \& Wang, C. K. J. (2019). Leisure nostalgia: Scale development and validation. Journal of Leisure Research. Advance online publication. doi: $10.1080 / 00222216.2019 .1602014$

Cho, H., Ramshaw, G., \& Norman, W. C. (2014). A conceptual model for nostalgia in the context of sport tourism: Re-classifying the sporting past. Journal of Sport \& Tourism, 19(2), 145-167.

Dimitrov, D. M. (2010). Testing for factorial invariance in the context of construct validation. Measurement and Evaluation in Counseling and Development, 43(2), 121-149. 
1 English, T., \& Chen, S. (2007). Culture and self-concept stability: Consistency across and within contexts among Asian Americans and European Americans. Journal of Personality and Social Psychology, 93(3), 478-490.

English, T., \& Chen, S. (2011). Self-concept consistency and culture: The differential impact of two forms of consistency. Personality and Social Psychology Bulletin, 37(6), 838849.

Fairley, S. (2003). In search of relived social experience: Group-based nostalgia sport tourism. Journal of Sport Management, 17(3), 284-304.

Fairley, S. (2009). The role of the mode of transport in the identity maintenance of sport fan travel groups. Journal of Sport \& Tourism, 14, 205-222.

Festinger, L. (1954). A theory of social comparison processes. Human Relations, 7(2), 117140.

Havlena, W. J., \& Holak, S. L. (1991). "The Good Old Days": Observations on nostalgia and its role in consumer behavior. Advances in Consumer Research, 18, 323-329.

Hogg, M. A., Terry, D. J., \& White, K. M. (1995). A tale of two theories: A critical comparison of identity theory with social identity theory. Social Psychology Quarterly, 58, 255-269.

Jackson, L. A., \& Wang, J. L. (2013). Cultural differences in social networking site use: A comparative study of China and the United States. Computers in Human Behavior, 29(3), 910-921.

Kacen, J. J., \& Lee, J. A. (2002). The influence of culture on consumer impulsive buying behavior. Journal of Consumer Psychology, 12(2), 163-176.

Kelloway, E. K. (1998). Using LISREL for structural equation modelling: A researcher's guide. Thousand Oaks, CA: Sage Publications, Inc. 
1 Muehling, D. D., \& Pascal, V. J. (2011). An empirical investigation of the differential effects of personal, historical, and non-nostalgic advertising on consumer responses. Journal of Advertising, 40(2), 107-122.

Seifried, C., \& Meyer, K. (2010). Nostalgia-related aspects of professional sport facilities: A facility audit of Major League Baseball and National Football League strategies to evoke the past. International Journal of Sport Management Recreation and Tourism, 5, 51-76.

Stern, B. B. (1992). Historical and personal nostalgia in advertising text: The fin de siecle effect. Journal of Advertising, 21(4), 11-22.

Tajfel, H., \& Turner, J. C. (1979). An integrative theory of intergroup conflict. In W. G. Austin \& S. Worche. (Eds.), The social psychology of intergroup relations (pp. 3347). Monterey, CA: Brooks-Cole Publishing Company.

Veal, A. J. (2016). Leisure, income inequality and the Veblen effect: Cross-national analysis of leisure time and sport and cultural activity. Leisure Studies, 35(2), 215-240. 
$1 \quad$ Table 1

2 Invariance of the Parameters

\begin{tabular}{clcccccc}
\hline Entry & Model Description & $\begin{array}{c}\text { Competing } \\
\text { model }\end{array}$ & $\chi^{2}$ & $d f$ & $\Delta \chi^{2}$ & $\Delta d f$ & $\begin{array}{c}\text { Statistical } \\
\text { Significance }\end{array}$ \\
\hline 1 & $\begin{array}{l}\text { Model with all parameters } \\
\text { unconstrained (Model 1) }\end{array}$ & - & 3149.07 & 970 & & & - \\
2 & $\begin{array}{l}\text { Model with all parameters } \\
\text { constrained to be equal }\end{array}$ & Model 1 & 4195.78 & 1046 & 1046.71 & 76 & $p<.01$ \\
\hline 3 & $\begin{array}{l}\text { Model with all factor loadings } \\
\text { constrained to be equal }\end{array}$ & Model 1 & 3226.87 & 1003 & 77.80 & 33 & $p<.01$ \\
4 & $\begin{array}{l}\text { Model with all covariances } \\
\text { constrained to be equal }\end{array}$ & Model 1 & 3159.74 & 980 & 10.67 & 10 & NS \\
\hline 5 & $\begin{array}{l}\text { Model with all error variances } \\
\text { to be equal }\end{array}$ & Model 1 & 4036.03 & 1003 & 886.96 & 33 & $p<.01$ \\
\hline
\end{tabular}

3

4 
$1 \quad$ Table 2

2 Invariance of the Factor Loadings

\begin{tabular}{|c|c|c|c|c|c|c|c|}
\hline Entry & Model Description & $\begin{array}{l}\text { Competing } \\
\text { model }\end{array}$ & $\chi^{2}$ & $d f$ & $\Delta \chi^{2}$ & $\Delta d f$ & $\begin{array}{c}\text { Statistical } \\
\text { significance* }\end{array}$ \\
\hline 1 & $\begin{array}{l}\text { Model with all parameters } \\
\text { unconstrained (Model 1) }\end{array}$ & - & 3149.07 & 970 & - & - & - \\
\hline 2 & $\begin{array}{l}\text { Model with all factor loadings } \\
\text { constrained to be equal }\end{array}$ & Model 1 & 3226.87 & 1003 & 77.80 & 33 & $p<.01$ \\
\hline 3 & $\begin{array}{l}\text { Model with all loadings on } \\
\text { 'Leisure Experience' constrained to } \\
\text { be equal (Model 2) }\end{array}$ & Model 1 & 3157.84 & 975 & 8.77 & 5 & NS \\
\hline 4 & $\begin{array}{l}\text { Model } 2 \text { plus all loadings on } \\
\text { 'Environment' constrained to be } \\
\text { equal (Model 3) }\end{array}$ & Model 2 & 3174.85 & 982 & 17.01 & 7 & NS \\
\hline 5 & $\begin{array}{l}\text { Model } 3 \text { plus all loadings on } \\
\text { 'Socialisation' constrained to be } \\
\text { equal }\end{array}$ & Model 3 & 3200.17 & 988 & 25.32 & 6 & $p<.01$ \\
\hline 6 & $\begin{array}{l}\text { Model } 3 \text { plus loading of S1 on } \\
\text { 'Socialisation' constrained to be } \\
\text { equal (Model 4) }\end{array}$ & Model 3 & 3175.48 & 983 & 0.63 & 1 & NS \\
\hline 7 & $\begin{array}{l}\text { Model } 4 \text { plus loading of S2 on } \\
\text { 'Socialisation' constrained to be } \\
\text { equal (Model 5) }\end{array}$ & Model 4 & 3176.08 & 984 & 0.60 & 1 & NS \\
\hline 8 & $\begin{array}{l}\text { Model } 5 \text { plus loading of } \mathrm{S} 3 \text { on } \\
\text { 'Socialisation' constrained to be } \\
\text { equal }\end{array}$ & Model 5 & 3195.59 & 985 & 19.51 & 1 & $p<.01$ \\
\hline 9 & $\begin{array}{l}\text { Model } 5 \text { plus loading of S4 on } \\
\text { 'Socialisation' constrained to be } \\
\text { equal }\end{array}$ & Model 5 & 3182.77 & 985 & 6.69 & 1 & $p<.01$ \\
\hline 10 & $\begin{array}{l}\text { Model } 5 \text { plus loading of } 55 \text { on } \\
\text { 'Socialisation' constrained to be } \\
\text { equal }\end{array}$ & Model 5 & 3187.35 & 985 & 11.27 & 1 & $p<.01$ \\
\hline 11 & $\begin{array}{l}\text { Model } 5 \text { plus loading of S6 on } \\
\text { 'Socialisation' constrained to be } \\
\text { equal (Model 6) }\end{array}$ & Model 5 & 3177.96 & 985 & 1.88 & 1 & NS \\
\hline 12 & $\begin{array}{l}\text { Model } 6 \text { plus all loadings on } \\
\text { 'Personal Identity' constrained to } \\
\text { be equal }\end{array}$ & Model 6 & 3199.11 & 992 & 21.15 & 7 & $p<.01$ \\
\hline 13 & $\begin{array}{l}\text { Model } 6 \text { plus loading of PI1 on } \\
\text { 'Personal Identity' constrained to } \\
\text { be equal }\end{array}$ & Model 6 & 3186.00 & 986 & 8.04 & 1 & $p<.01$ \\
\hline 14 & $\begin{array}{l}\text { Model } 6 \text { plus loading of PI } 2 \text { on } \\
\text { 'Personal Identity' constrained to } \\
\text { be equal }\end{array}$ & Model 6 & 3190.74 & 986 & 12.78 & 1 & $p<.01$ \\
\hline 15 & $\begin{array}{l}\text { Model } 6 \text { plus loading of PI3 on } \\
\text { 'Personal Identity' constrained to } \\
\text { be equal (Model 7) }\end{array}$ & Model 6 & 3181.64 & 986 & 3.68 & 1 & NS \\
\hline 16 & $\begin{array}{l}\text { Model } 7 \text { plus loading of PI } 4 \text { on } \\
\text { 'Personal Identity' constrained to } \\
\text { be equal }\end{array}$ & Model 7 & 3192.53 & 987 & 10.89 & 1 & $p<.01$ \\
\hline 17 & $\begin{array}{l}\text { Model } 7 \text { plus loading of PI5 on } \\
\text { 'Personal Identity' constrained to } \\
\text { be equal (Model 8) }\end{array}$ & Model 7 & 3186.28 & 987 & 4.64 & 1 & NS \\
\hline 18 & $\begin{array}{l}\text { Model } 8 \text { plus loading of PI6 on } \\
\text { 'Personal Identity' constrained to } \\
\text { be equal (Model 9) }\end{array}$ & Model 8 & 3186.75 & 988 & 0.47 & 1 & NS \\
\hline
\end{tabular}




\begin{tabular}{llllllll}
\hline 19 & $\begin{array}{l}\text { Model 9 plus loading of PI7 on } \\
\text { 'Personal Identity' constrained to } \\
\text { be equal (Model 10) }\end{array}$ & Model 9 & 3186.77 & 989 & 0.02 & 1 & NS \\
\hline 20 & $\begin{array}{l}\text { Model 10 plus all loadings on } \\
\text { 'Group Identity' constrained to be } \\
\text { equal }\end{array}$ & Model 10 & 3196.41 & 997 & 9.64 & 8 & \\
\hline
\end{tabular}

*Significance level: $p=.01$

2

3

4

5

6

7

8

9

10

11

12

13

14

15

16

17

18

19

20

21

22 
$1 \quad$ Table 3

2 A Summary of the Findings with the Standardised (Unstandardised) Factor Loadings

\begin{tabular}{|c|c|c|c|}
\hline Items: __ evoke(s) my nostalgic feelings. & $\begin{array}{l}\text { Singapore } \\
(n=448)\end{array}$ & $\begin{array}{c}\mathrm{UK} \\
(n=207)\end{array}$ & $\begin{array}{c}\text { Invariant } \\
\text { item? }\end{array}$ \\
\hline \multicolumn{4}{|l|}{ Leisure Experience } \\
\hline (LE1) Remembering my leisure activity that I enjoyed & $0.91(.82)$ & $1.07(.83)$ & Yes \\
\hline (LE2) My exciting leisure experience in the past & $0.90(.81)$ & $1.14(.85)$ & Yes \\
\hline $\begin{array}{l}\text { (LE3) Remembering the freedom I experienced during my } \\
\text { favorite leisure activity }\end{array}$ & $0.83(.72)$ & $1.01(.68)$ & Yes \\
\hline (LE4) Free time I had during my favorite leisure activity & $0.87(.65)$ & $0.92(.63)$ & Yes \\
\hline (LE5) Recharging myself through leisure activity & $0.68(54)$ & $0.79(.48)$ & Yes \\
\hline \multicolumn{4}{|l|}{ Environment } \\
\hline (E1) The food I ate during my favorite leisure time period & $0.87(.57)$ & $0.86(.49)$ & Yes \\
\hline (E2) The appearance of my favorite leisure place & $0.86(.65)$ & $0.90(.56)$ & Yes \\
\hline (E3) Memorable weather during my favorite leisure time & $1.02(.71)$ & $0.94(.52)$ & Yes \\
\hline (E4) The practical design of my favorite leisure place & $1.23(.88)$ & $1.31(.78)$ & Yes \\
\hline (E5) The architectural design of my favorite leisure place & $1.25(.84)$ & $1.44(.80)$ & Yes \\
\hline (E6) The leisure activity equipment I used & $0.78(.60)$ & $1.11(.60)$ & Yes \\
\hline (E7) The size of my favorite leisure place & $1.04(.73)$ & $1.47(.78)$ & Yes \\
\hline \multicolumn{4}{|l|}{ Socialisation } \\
\hline (S1) Friends participating in leisure activity with me & $0.96(.82)$ & $1.08(.70)$ & Yes \\
\hline $\begin{array}{l}\text { (S2) Positive memories shared with others during my favorite } \\
\text { leisure activity }\end{array}$ & $0.90(.86)$ & $1.03(.76)$ & Yes \\
\hline $\begin{array}{l}\text { (S3) Memories of building friendships with others during my } \\
\text { favorite leisure activity }\end{array}$ & $0.96(.90)$ & $1.36(.90)$ & No \\
\hline (S4) Memories of socialising with others during my favorite leisure & $0.98(.87)$ & $1.26(.88)$ & No \\
\hline (S5) Memories of making new friends during my favorite leisure & $1.02(.82)$ & $1.40(.87)$ & No \\
\hline (S6) Entertainments enjoyed with others during my leisure activity & $0.78(.67)$ & $0.99(.66)$ & Yes \\
\hline \multicolumn{4}{|l|}{ Personal Identity } \\
\hline (PI1) Identifying myself as a lover of my favorite leisure activity & $0.97(.82)$ & $1.32(.85)$ & No \\
\hline (PI2) Pride in being a lover of my favorite leisure activity & $1.03(.87)$ & $1.43(.90)$ & No \\
\hline $\begin{array}{l}\text { (PI3) A feeling of satisfaction as a loyal leisure participant of my } \\
\text { favorite leisure activity }\end{array}$ & $1.01(.89)$ & $1.27(.84)$ & Yes \\
\hline $\begin{array}{l}\text { (PI4) Positive feelings about myself as a lover of my favorite } \\
\text { leisure activity }\end{array}$ & $0.98(.85)$ & $1.41(.87)$ & No \\
\hline (PI5) My value as a leisure participant & $0.82(.71)$ & $1.17(.73)$ & Yes \\
\hline (PI6) Sense of accomplishment as a leisure participant & $0.79(.68)$ & $1.03(.65)$ & Yes \\
\hline (PI7) Being loyal to my favorite leisure activity & $0.95(.73)$ & $1.17(.68)$ & Yes \\
\hline \multicolumn{4}{|l|}{ Group Identity } \\
\hline (GI1) Unique characteristics of my leisure social group & $0.94(.75)$ & $1.23(.69)$ & Yes \\
\hline (GI2) The traditions of my leisure group & $1.00(.73)$ & $1.01(.60)$ & Yes \\
\hline (GI3) Group rituals at the leisure place & $1.04(.71)$ & $1.15(.69)$ & Yes \\
\hline $\begin{array}{l}\text { (GI4) Shared memories which affected my group identity at the } \\
\text { leisure place }\end{array}$ & $1.17(.87)$ & $1.26(.74)$ & Yes \\
\hline $\begin{array}{l}\text { (GI5) History of my group that shared a lot in common with my } \\
\text { group members }\end{array}$ & $1.16(.89)$ & $1.42(.82)$ & Yes \\
\hline (GI6) Pride of being a part of my group at the leisure place & $1.17(.88)$ & $1.39(.83)$ & Yes \\
\hline (GI7) Experiences of group bonding during my leisure activity & $1.11(.86)$ & $1.41(.85)$ & Yes \\
\hline (GI8) How important I was to the members of my leisure group & $1.11(.82)$ & $1.33(.80)$ & Yes \\
\hline
\end{tabular}




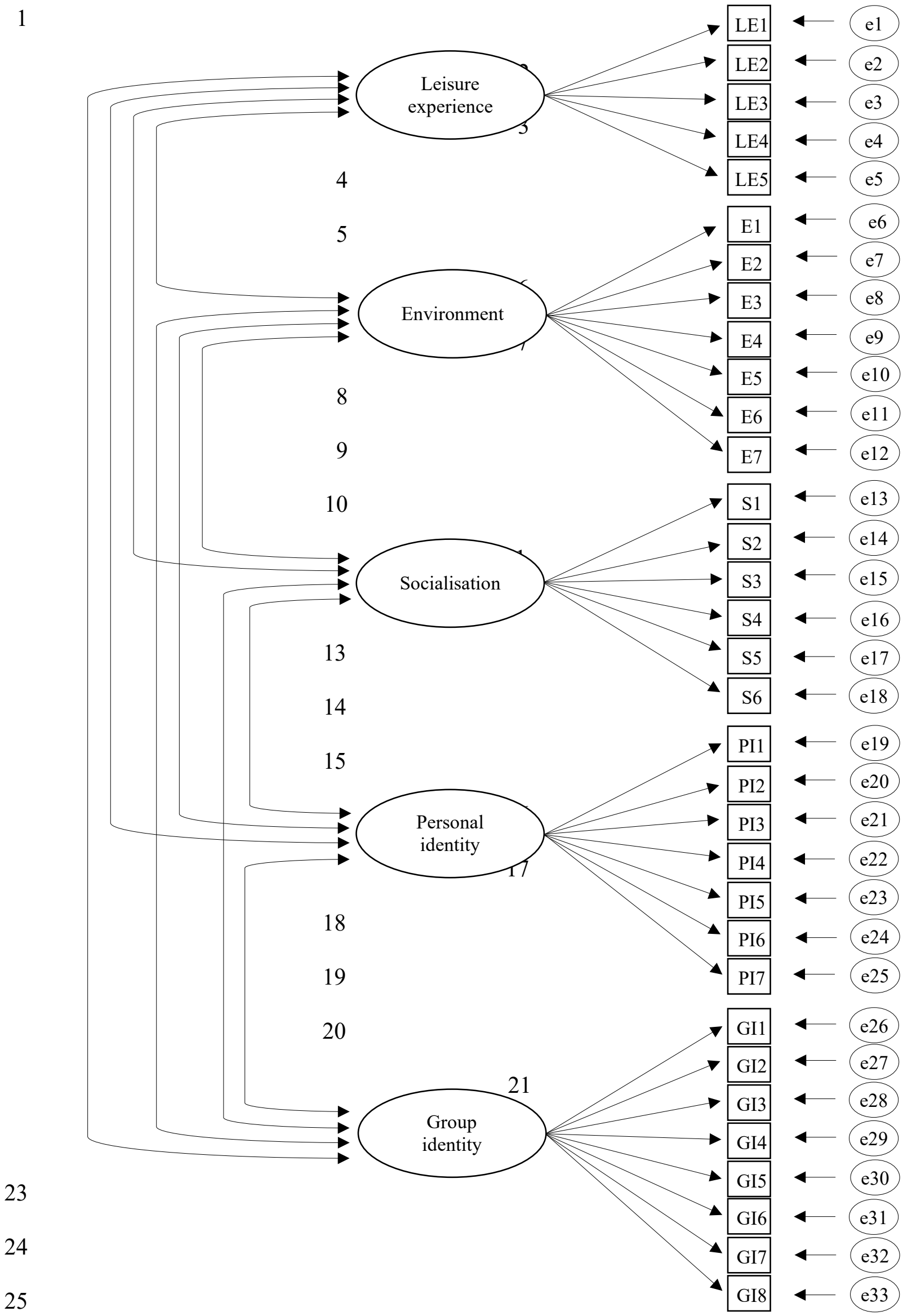

26 Figure 1. The hypothesised measurement model for leisure nostalgia 